\title{
Customer incivility and service sabotage in the hotel industry
}

\begin{abstract}
Purpose: Using equity theory, this study aims to examine the role of customer incivility in affecting service sabotage among hotel employees by recognizing the mediating role of revenge motivation and the moderating effect of emotion regulation.
\end{abstract}

Design/methodology/approach: A multi-wave, multi-source questionnaire survey was conducted with 291 employee-supervisor dyads at chain hotels in Shenzhen City, China. Previously developed and validated measures for customer incivility, revenge motivation, emotion regulation, and service sabotage were adopted to test the hypotheses.

Findings: Customer incivility increased employees' revenge motivation and service sabotage. Emotion regulation acted as a boundary condition for customer incivility's direct effect on revenge motivation and its indirect effect on service sabotage through revenge motivation. Cognitive reappraisal mitigated the detrimental influence of customer incivility, whereas expressive suppression worsened its adverse effects.

Practical implications: Managers should monitor and deter the emergence of uncivil behaviors, provide psychological support for employees experiencing customer incivility and encourage these employees to use cognitive reappraisal rather than expressive suppression as an emotion regulation strategy.

Originality/value: To our knowledge, no prior research has investigated the customer incivility-service sabotage relationship in the hotel industry. This study sheds light on how customer incivility can motivate service sabotage among hotel employees. Furthermore, we used equity theory rather than the commonly adopted resources perspective to offer new insights into the customer incivility-service sabotage relationship.

Keywords: customer incivility, revenge motivation, emotion regulation, service sabotage, equity theory

Article classification: Research paper 


\section{Introduction}

In the past few decades, the growth of the service industry has led to an increase in servicerelated jobs. Unfortunately, customer incivility has also increased, and service employees are frequently exposed to "daily hassles" during the customer service process (Arnold and Walsh, 2015; Sliter et al., 2010, 2012; Wilson and Holmvall, 2013). Prior research has established that frontline employees are exposed to prolonged periods in a service setting (Torres et al., 2017). Consequently, employees in the hospitality industry (e.g., restaurants or hotels) are significantly more likely than those in other industries to experience customer incivility (Huang and Miao, 2016; Torres et al., 2017). Occasional incivility should not be particularly stressful; however, repeated uncivil behaviors can create stress and lead to negative responses (Kim and Qu, 2019; Sliter et al., 2012). Thus, it is imperative to explore how customer incivility influences service employees' behaviors in hospitality contexts.

Several studies have examined customer incivility in hospitality contexts (e.g., Cho et al., 2016; Han et al., 2016; Hur et al., 2016; Kim and Qu, 2019; Torres et al., 2017; Wilson and Holmvall, 2013). However, a critical area that has not received much attention is the connection among customer incivility, hotel employees' negative responses, and the impact on work performance (Hur et al., 2016; Torres et al., 2017). To address this issue, this study focuses on the association between customer incivility and service sabotage-a deviant behavior by hotel frontline service employees. As a subtle form of mistreatment (Kern and Grandey, 2009), customer incivility can adversely affect employees' attitude and performance (Sliter et al., 2010; van Jaarsveld et al., 2010) and increase the likelihood of service sabotage. Therefore, we propose that service sabotage may be an important behavioral consequence of customer incivility among service employees in the hotel industry.

Previous studies have indicated that customer incivility can deplete service employees' valuable resources (e.g., emotional resources) (Cho et al., 2016; Hur et al., 2015; van Jaarsveld et al., 2010) and increase the risk of negative consequences, such as burnout (Kim and Qu, 2019; Sliter et al., 2010) and withdrawal (Sliter et al., 2012). Most prior studies have adopted the resources perspective (e.g., Han et al., 2016; Walker et al., 2017; Wang et al., 2011; Wilson and Holmvall, 2013; etc.), but the present study argues that this perspective alone cannot fully 
explain the effect of customer incivility on service sabotage. Although a lack of resources may hinder employees from acting proactively (e.g., may trigger a desire for avoidance and resultant withdrawal behaviors), it cannot explain the motivations for revenge or retaliatory actions, such as sabotaging service (Gregoire et al., 2009). This research, therefore, uses equity theory to examine the employee-customer social exchange and the potential effect of incivility on service sabotage.

Customer incivility can be considered as a negative social exchange between customers and employees (Walker et al., 2014). In these negative exchanges, the returns that employees receive (i.e., incivility rather than courtesy and respect) do not match the resources that they have invested (i.e., time, emotion, and energy). This discrepancy increases employees' perceptions that they are not being treated justly by the customers, which can lead to retaliatory actions, such as service sabotage. These violations can also cause employees to develop a "tit for tat" mentality (Andersson and Pearson, 1999; Walker et al., 2017). Thus, employees might engage in acts of service sabotage to retaliate against uncivil customers (Abubakar and Arasli, 2016; Skarlicki et al., 2016). Therefore, this study predicted that revenge motivation could serve as a vital mediating mechanism in the customer incivility-service sabotage relationship.

This study also aimed to elucidate the conditions under which the adverse effects of customer incivility are amplified or mitigated. Hence, it examined the moderating role of emotion regulation, which includes two strategies for coping with cognitive events: cognitive reappraisal and expressive suppression (Gross, 1998; Spaapen et al., 2014). Employees who use cognitive reappraisal when faced with uncivil behaviors will reevaluate stressful situations (Gross and John, 2003) and try to decrease their feelings of unjust treatment, thereby reducing negative emotions. As such, their revenge motivation may be buffered. Conversely, employees using expressive suppression strategies might experience a dissonance between their inner feelings and outer expressions (Gross and John, 2003); this dissonance can emphasize feelings of inequity and trigger revenge motivation. Therefore, different emotion regulation strategies provide valuable boundary conditions to examine the effects of customer incivility on revenge motivation and expand our knowledge of how and when customer incivility increases employees' revenge motivation. 


\section{Theoretical background and hypotheses}

\section{Customer incivility}

Andersson and Pearson (1999) defined workplace incivility as a "low-intensity deviant behavior with ambiguous intent to harm the target, in violation of workplace norms for mutual respect" (p. 457). Incivility appears not only in employee-employee interactions, but also in employee-customer interactions, in which employees frequently experience unfriendly and impolite treatment by customers (Kern and Grandey, 2009; Sliter et al., 2010). In service occupations, most employees face uncivil behaviors more often from customers than from colleagues. This might be due to the following reasons: (1) service employees communicate with clients more frequently than with colleagues (Wilson and Holmvall, 2013); (2) employees have less power in the employee-customer relationship (Henkel et al., 2017; Hur et al., 2015; Sliter et al., 2010); and (3) customers in service encounters are more likely to be strangers (Kern and Grandey, 2009). Therefore, following Andersson and Pearson's (1999) definition of workplace incivility, customer incivility has been defined as a "low-intensity deviant behavior, perpetrated by someone in a customer or client role, with ambiguous intent to harm an employee, in violation of social norms of mutual respect and courtesy" (Sliter et al., 2010, p. 468). Examples of customer incivility include not saying "thank you", talking on the phone while service is being provided (Sliter et al., 2010), or speaking in an uncivil manner (van Jaarsveld et al., 2010).

Previous studies have identified five main characteristics of customer incivility. First, customer incivility is a type of low-intensity behavior. Unlike high-intensity behaviors—such as aggression (Ben-Zur and Yagil, 2005), mistreatment (Shao and Skarlicki, 2014) and abuse (Kashif et al., 2017) — customer incivility does not involve physical contact and tends to involve less overt behaviors, such as slighting or ignoring service employees (Cortina and Magley, 2009). Second, the motives for incivility tend to be ambiguous; namely, customers may display incivility out of ignorance or negligence, rather than an intent to cause harm (Kim and Qu, 2019; Sliter et al., 2010; Torres et al., 2017), unlike aggression, mistreatment and abuse, which have clear objectives of assault (Sliter et al., 2012). Third, customer incivility can be difficult 
to detect and monitor (Walker et al., 2014). Whereas mutual respect and courtesy are implicit social norms, people can have different understandings of these norms, which makes incivility difficult to observe (Arnold and Walsh, 2015). Fourth, as acts of customer incivility are difficult to detect, they might not be considered threatening (Torres et al., 2017) and are easily neglected by managers, resulting in increased frequency. Finally, as a subtle deviant behavior (Kern and Grandey, 2009), occasional customer incivility might not be considered stressful, but with repeated instances over time, it can produce stress and have negative consequences (Kim and Qu, 2019; Sliter et al., 2012). Customer incivility is, therefore, a crucial stressor for service employees (Kern and Grandey, 2009) and can adversely affect their performance (Sliter et al., 2010; van Jaarsveld et al., 2010).

\section{Customer incivility and service sabotage}

Service sabotage, as an extension of workplace sabotage in the service industry (Skarlicki et al., 2008), is defined as the intentional behavior of frontline service employees to interrupt customer service and harm customers' interests (Chi et al., 2015; Harris and Ogbonna, 2002; Lee and Ok, 2014; Wang et al., 2011). It is a type of deviant behavior that goes against organizational norms and imperils the welfare of organizations and their members (Bennett and Robinson, 2000; Robinson and Bennett, 1995). Workplace sabotage is common among employees in traditional industries (e.g., manufacturing factories). Employees might disrupt normal operations by being uncooperative, hiding useful information, transmitting incorrect information, destroying work tools, or attempting to undermine interpersonal relationships in the organization (Ambrose et al., 2002; Crino, 1994; Skarlicki et al., 2008). In those cases, the saboteur has a clear target: the organization (Ambrose et al., 2002; Crino, 1994).

In service industry sabotage, the target shifts from the organization to the customer (Lee and Ok, 2014). Service sabotage in the hotel industry takes place during the customer service process and can assume many forms. For example, employees dealing with food and beverages might deliberately slow down the service or intentionally ignore, embarrass, or show hostility toward the customers; those in the housekeeping department might intentionally fail to keep the rooms perfectly clean; and those on the front desk might receive customers discourteously 
or refuse to provide them with comprehensive and accurate information (Harris and Ogbonna, 2006; Lee and Ok, 2014; Skarlicki et al., 2008; Wang et al., 2011; Zhou et al., 2018). The negative effects of the sabotage on the customers' perceptions of service quality can hinder enterprises from gaining competitive advantages (Skarlicki et al., 2016). Thus, it is important to uncover the precursors of service sabotage and the reasons for its emergence.

Sabotage has been documented as retaliatory in nature (Ambrose et al., 2002; Skarlicki et al., 2008). The stressful situations created by customer incivility can incentivize employees to carry out sabotage. When viewed through the prism of equity theory, customer incivility represents a poor social exchange between employees and customers (Walker et al., 2014), which generates feelings of unfairness among employees (Andersson and Pearson, 1999; Wang et al., 2011) and results in retaliatory service sabotage (Bedi and Schat, 2017; Skarlicki et al., 2008; Skarlicki et al., 2016).

Specifically, service delivery is not always a simple unilateral process between a provider and a recipient: effective interactions and consensus between the two actors can be more important than simple delivery (Surprenant and Solomon, 1987). For example, when customers check into a hotel, service employees must first communicate with them about how long they will stay, their room preferences, and so on. The social exchange does not end after the checkin, and employees might provide ongoing services until the clients leave the hotel. A significant time investment is required from the employees to ensure high-quality service, and the customers' response to such investment can shape employees' perceptions of the social interaction. They might compare their work inputs (e.g., time, emotion, energy) to their work returns (e.g., respect, politeness, compliments from customers) and attempt to achieve equity between the two (Adams, 1963, 1965). When employees detect customer incivility during the service process, they perceive an unequal tradeoff between investments and returns, which can lead to perceptions of unfairness in the employee-customer social exchange and result in stress (Andersson and Pearson, 1999; Wang et al., 2011; Walker et al., 2014). Employees might, therefore, employ "tit for tat" responses (e.g., service sabotage) to damage the interests of the perpetrators of the incivility (Bedi and Schat, 2017; Skarlicki et al., 2008, 2016). Thus, we propose: 
H1. Customer incivility is positively related to service sabotage.

\section{Mediating role of revenge motivation}

Revenge motivation is the intention of employees to punish and cause harm to a target (e.g., a customer) for the damage caused to them (Gregoire et al., 2009; Yeh, 2015). On the basis of equity theory, individuals attend to pursue equity between the efforts they devote to work (inputs) and the resulting outcomes (outputs) (Adams, 1963, 1965; Greenberg, 1987). Customer incivility may cause employees to sense an imbalance between efforts and returns, which can lead to a desire to punish the perpetrators of incivility and increase revenge motivation.

Equity theory further suggests that individuals are sensitive to unjust situations and are inclined to act to restore equity (Adams, 1963, 1965; Schumann and Ross, 2010). Customer incivility violates norms of mutual respect, and victimized employees may feel unfairly treated. To restore equity and decrease the sense of unfairness, employees may engage in acts of retaliation motivated by a desire for revenge (Bedi and Schat, 2017; Yeh, 2015). Hence, we propose:

H2. Revenge motivation mediates the effect of customer incivility on service sabotage.

\section{Moderating effect of emotion regulation}

Emotion regulation plays a crucial role in social interactions (Spaapen et al., 2014). For instance, when individuals adopt adaptive emotion regulation, the negative effects of stressful situations are relatively weak (Shorey et al., 2015). Thus, the intensity of the effects of customer incivility on revenge motivation may differ between employees, depending on their emotion regulation strategies.

Individuals normally employ one of two emotion regulation strategies: cognitive reappraisal or expressive suppression (Gross, 1998; Gross and John, 2003; Spaapen et al., 2014). Cognitive reappraisal is regarded as an antecedent-focused strategy (e.g., changing one's thinking about a stressful situation), whereas expressive suppression is considered responsefocused (e.g., controlling negative emotions by not expressing them) (Gross and John, 2003). Overall, individuals who regularly choose expressive suppression tend to experience more 
negative effects (e.g., anxiety, depression, nervousness), whereas those who use cognitive reappraisal experience fewer negative effects (Joormann and Gotlib, 2010) and better interpersonal functioning (Gross and John, 2003).

Emotion regulation strategies not only have different adaptive-emotional outcomes (Gross, 1998), but can amplify or mitigate the feelings of unfairness and the revenge motivation experienced by employees facing customer incivility. For example, employees who adopt cognitive reappraisal might think that the customers are not intentionally being uncivil, or they might examine their own service processes in response to the incivility. As a result, there may be fewer feelings of unjust treatment and fewer negative emotions. Cognitive reappraisal may therefore be an effective mechanism for reducing the stress caused by customer incivility and may weaken the positive effect of customer incivility on revenge motivation.

On the other hand, in expressive suppression, controlling rather than expressing negative emotions creates a dissonance between inner feelings and outer expressions (Gross and John, 2003), increasing the risk of negative effects (Gross and John, 2003; Joormann and Gotlib, 2010). The adoption of expressive suppression in the face of customer incivility can emphasize employees' feelings of inequity, which may strengthen the revenge motivation. Therefore, we propose:

H3. Cognitive reappraisal moderates the positive relationship between customer incivility and revenge motivation, such that the relationship is weaker when individuals' cognitive reappraisal is high.

H4. Expressive suppression moderates the positive relationship between customer incivility and revenge motivation, such that the relationship is stronger when individuals' expressive suppression is high.

Given the reasons mentioned above, we further develop an integrated conceptual framework in which revenge motivation mediates the effect of customer incivility on service sabotage, and emotion regulation moderates the relationship between customer incivility and revenge motivation. In other words, the indirect effect of customer incivility on service sabotage through revenge motivation will be weaker among employees who hold high levels of cognitive reappraisal and stronger for those who hold high levels of expressive suppression. 
Hence, we propose:

H5. The indirect effect of customer incivility on service sabotage via revenge motivation is moderated by individuals' cognitive reappraisal, such that this relationship is weaker when individuals' cognitive reappraisal is high.

H6. The indirect effect of customer incivility on service sabotage via revenge motivation is moderated by individuals' expressive suppression, such that this relationship is stronger when individuals' expressive suppression is high.

The conceptual model is illustrated in Figure 1.

[Figure 1 near here]

\section{Method}

Sample and procedures

Shenzhen City in China is a metropolis of modern skyscrapers and shopping malls situated close to Hong Kong. For this study, we randomly selected 25 chain hotels from a list of the 50 most popular hotels in the city, as published on CTRIP.com. We invited the 25 hotels to take part in our research: 9 agreed, including 3 budget hotels, 3 three-star hotels, 2 four-star hotels and 1 five-star hotel. To minimize common method bias, we conducted multi-wave and multisource surveys using the questionnaires (Podsakoff et al., 2012). A time-lagged research design was adopted, with three waves of data obtained from service employees and their supervisors at two-month intervals. The first wave survey (T1) measured customer incivility, emotion regulation and related demographic information (gender, age, education, and tenure). The second (T2) was conducted two months later and measured employees' revenge motivation. The third (T3) was administered two months after T2, and the supervisors were asked to evaluate employees' service sabotage.

The surveys were conducted with the support of human resources managers. We obtained a list of employees from the departments of housekeeping, food and beverages, and front desk (including the check-out counter), as they frequently interact with customers. A total of 80-150 employees for each hotel (depending on the hotel's size) were randomly chosen and invited to participate in the study; in total, 968 available respondents were obtained. We numbered each respondent to match the employees with their supervisors. We put the questionnaires in 
envelopes and marked each envelope and questionnaire with a unique identifier. They were distributed on-site and retrieved after completion. To ensure honest and accurate responses, we explained to all the participants that their anonymity and privacy would be respected.

In T1, we distributed questionnaires to 968 employees, and received 723 usable answers (response rate: $74.7 \%$ ). In T2, we sent the second survey to the employees who had responded the first time, and 492 valid ones were returned (response rate: 68.1\%). In T3, questionnaires were distributed to 70 direct supervisors of the 492 employees who had provided valid responses in the second wave (on average, each supervisor evaluated 7.0 employees): 291 valid questionnaires were returned by 52 supervisors (response rate: 59.2\%). Of these 291 employees, $70.1 \%$ were female, $14.4 \%$ were 20 years old or younger, $39.2 \%$ were aged between 21 and 30 , $18.6 \%$ between 31 and $40,12.7 \%$ between 41 and 50, and $15.1 \%$ were 51 or older. In terms of education, $67.0 \%$ held a high school degree or below, $22.4 \%$ had a junior college degree, and the remaining $10.6 \%$ held a bachelor's degree or above. As for tenure, $35.4 \%$ had worked for one year or less, nearly half (48.1\%) had worked for two to five years, and a relatively small proportion (16.5\%) had worked for longer than five years. A total of $43.3 \%$ worked in housekeeping, $24.1 \%$ in food and beverages, and $32.6 \%$ on the front desk.

\section{Measures}

The measures used in this study were originally developed in English but administered in Chinese. Therefore, to guarantee the accuracy and reliability of this measures, we followed the back-translated approach to translate the items from English to Chinese (Brislin, 1970). In addition, to ensure that all items were applicable to the current research context, a human resources manager and ten frontline service employees from a hotel were invited to evaluate the content (this hotel was not included in our formal study). Based on their feedbacks, minor modifications were made to ensure the generalizability of all the items. The respondents rated the measures on a 5-point Likert-type scale ranging from 1 (strongly disagree) to 5 (strongly agree). Appendix A shows the items for each construct.

Customer incivility. We measured customer incivility using Walker et al.'s (2014) 4-item scale. A sample item was "My customers spoke aggressively toward me." (Cronbach's alpha= 
$0.78)$.

Revenge motivation. We measured revenge motivation using McCullough et al.'s (1998) 5-item scale. A sample item was "I wanted to see the customer hurt and miserable." (Cronbach's alpha $=0.79)$.

Emotion regulation. We measured emotion regulation using Spaapen et al.'s (2014) 9-item scale; 5 items measured cognitive reappraisal, and 4 measured expressive suppression. A sample item for cognitive reappraisal was "I control my emotions by changing the way I think about the situation I'm in"; a sample item for expressive suppression was "When I am feeling positive emotions, I am careful not to express them." The Cronbach's alphas for cognitive reappraisal and expressive suppression were 0.72 and 0.75 , respectively.

Service sabotage. We measured service sabotage using Chi et al.'s (2015) 6-item scale. A sample item was "This employee mistreats customers deliberately." (Cronbach's alpha $=0.94)$.

Control variables. We controlled for gender, age, education, and tenure in our analyses because of their potential effects on service performance (Chi and Grandey, 2019; Lyu et al., 2016; Zhou et al., 2018).

\section{Results}

Non-response bias and common method bias

Following Armstrong and Overton (1977), we examined the non-response bias to ensure that validity was not threatened. We divided the sample into two sub-groups - early and late respondents - and compared them in terms of control variables (i.e., demographic characteristics) and key variables (i.e., customer incivility, revenge motivation, cognitive reappraisal, expressive suppression and service sabotage). The results showed no significant differences among those variables $(p>0.05)$, demonstrating that non-response bias was not a problem.

Although we administered the surveys to multiple sources (service employees and their supervisors), the control variables and several key variables were self-reported by the employees, leading to the possibility of common method bias (Podsakoff et al., 2003). To address this issue, we followed Harman (1976) and used a single-factor test to examine the 
potential impact of common method bias. The results indicated that six factors had eigenvalues greater than 1, and the first factor accounted for $27.89 \%$ of the total variance. Accordingly, we concluded that common method bias was not a serious issue, since several factors appeared, and the first factor constituted a small proportion of the total variance (Podsakoff et al., 2003).

\section{Confirmatory factor analyses}

We conducted confirmatory factor analyses (CFAs) to examine the distinctiveness of the key variables (i.e., customer incivility, revenge motivation, cognitive reappraisal, expressive suppression and service sabotage) (Anderson and Gerbing, 1988). The results of CFAs presented in Table 1 show that the baseline model (five-factor measurement model including five key variables) yielded a better fit $\left(\chi^{2}=522.44, \mathrm{df}=239, \mathrm{IFI}=0.92, \mathrm{CFI}=0.92\right.$, RMSEA $=0.06$.) than other several alternative measurement models (Cheung and Rensvold, 2002). Thus, the discriminant validity of the five variables was confirmed. Moreover, all factor loadings were significant, indicating convergent validity.

\section{[Table 1 near here]}

\section{Descriptive statistics}

Table 2 presents the means, standard deviations and correlations of the control variables and key variables. The results show that customer incivility was positively related to revenge motivation $(r=0.42, p<0.01)$ and service sabotage $(r=0.32, p<0.01)$. Moreover, revenge motivation was positively related to service sabotage $(r=0.31, p<0.01)$, offering initial support for the hypotheses.

\section{[Table 2 near here]}

\section{Hypothesis testing}

Hypothesis 1 was tested using hierarchical multiple regression analysis. To test H1, we identified service sabotage as the dependent variable and entered the control variables and customer incivility in separate steps. The results, as shown in Table 3, indicate that customer incivility was positively associated with service sabotage $(\beta=0.30, p<0.01$, Model 7), thus supporting H1.

[Table 3 near here] 
To examine the mediation effect of revenge motivation (Hypothesis 2), we used the Hayes PROCESS model (Hayes, 2013). The indirect effect was estimated at 0.13 , with a $95 \%$ biascorrected confidence interval $[0.06,0.22]$. Since the range of its indirect effect's $95 \%$ biascorrected confidence interval does not contain 0 , the indirect effect of customer incivility on service sabotage via revenge motivation was considered statistically significant. Hence, H2 is supported. Furthermore, the results in Table 3 indicate that customer incivility was positively associated with revenge motivation $(\beta=0.41, p<0.01$, Model 2 ), and that revenge motivation was positively associated with service sabotage $(\beta=0.29, p<0.01$, Model 8$)$. Compared to the direct effect of customer incivility on service sabotage $(\beta=0.30, p<0.01$, Model 7$)$, the inclusion of revenge motivation decreased customer incivility's positive effect on service sabotage $(\beta=0.22, p<0.01$, Model 9), whereas revenge motivation continued to have a positive effect on service sabotage $(\beta=0.20, p<0.01$, Model 9). This demonstrated a partial mediating effect of revenge motivation on the customer incivility-service sabotage relationship. Hence, $\mathrm{H} 2$ receives further support.

Moderated regression analyses were used to examine hypotheses 3 and 4 (the moderating roles of cognitive reappraisal and expressive suppression, respectively). First, we meancentered the independent variable (customer incivility) and the moderating variables (cognitive reappraisal and expressive suppression) to avoid issues of multicollinearity (Aiken and West, 1991). As seen in Table 3, the interaction between customer incivility and cognitive reappraisal was negatively associated with revenge motivation $(\beta=-0.11, p<0.05$, Model 4$)$, while the interaction between customer incivility and expressive suppression was positively associated with revenge motivation $(\beta=0.15, p<0.01$, Model 4$)$. To better comprehend the different moderating effects, we plotted the interactions by computing slopes one standard deviation above and one standard deviation below the mean of each moderator (Aiken and West, 1991). Figures 2 and 3 present the different interaction patterns of cognitive reappraisal and expressive suppression, consistent with hypotheses 3 and 4, respectively. As shown in Figure 2, customer incivility was more positively associated with revenge motivation when cognitive reappraisal was low $(\beta=0.34, p<0.01)$ than when it was high $(\beta=0.19, p<0.01)$. Conversely, as showed in Figure 3, customer incivility was less positively associated with revenge motivation when 
expressive suppression was low $(\beta=0.15, p<0.01)$ rather than high $(\beta=0.38, p<0.01)$. Hence, $\mathrm{H} 3$ and $\mathrm{H} 4$ are supported.

\section{[Figures 2 and 3 near here]}

Moderated path analyses were performed to test hypotheses 5 and 6 (cognitive reappraisal and expressive suppression, respectively, moderate the indirect effect of customer incivility on service sabotage via revenge motivation) (Edwards and Lambert, 2007). Regarding H5, the results showed that the indirect effect of customer incivility on service sabotage via revenge motivation varied significantly across different levels of cognitive reappraisal $(\Delta \beta=-0.05, p<$ 0.05). Specifically, this indirect effect was stronger when cognitive reappraisal was low ( $\beta=$ 0.13, $p<0.01)$ than when it was high $(\beta=0.08, p<0.01)$. Hence, H5 received support. Furthermore, this indirect effect varied significantly across different levels of expressive suppression $(\Delta \beta=0.07, p<0.01)$. Specifically, it was stronger when expressive suppression was high $(\beta=0.13, p<0.01)$ than when it was low $(\beta=0.06, p<0.01)$. Hence, H6 received support.

\section{Discussion and Conclusions}

\section{Conclusions}

This study adopted the framework of equity theory to examine how and when customer incivility leads to service sabotage in the hotel industry. It also investigated the mediating role of revenge motivation and the moderating role of different emotion regulation strategies (i.e., cognitive reappraisal and expressive suppression). Using data gathered through a time-lagged research design, we concluded that customer incivility positively affects employees' revenge motivation, which, in turn, increases service sabotage. We also found that emotion regulation plays a significant moderating role in the direct effect of customer incivility on revenge motivation and its indirect effect on service sabotage through revenge motivation. Specifically, cognitive reappraisal reduced the effect of customer incivility on revenge motivation and also acted as a buffer for its indirect effect on service sabotage through revenge motivation. However, expressive suppression may reinforce the effect of customer incivility on revenge motivation, as well as its indirect effect on service sabotage via revenge motivation. 


\section{Theoretical implications}

This study makes several theoretical contributions. First, we advance current knowledge on customer incivility by examining its consequences (i.e., service sabotage). Some scholars have explored the adverse effects of customer incivility on employees in various service industries, such as retail (Kern and Grandey, 2009; Wilson and Holmvall, 2013), department stores (Hur et al., 2015), call centers (van Jaarsveld et al., 2010), banks (Sliter et al., 2010; Sliter et al., 2012), insurance companies (Walker et al., 2014), and restaurants (Cho et al., 2016; Han et al., 2016; Kim and Qu, 2019; Wilson and Holmvall, 2013). However, only a few of them focused on hotel service employees (Hur et al., 2016; Torres et al., 2017). As far as we know, no previous study has investigated the relationship between customer incivility and service sabotage in the hotel industry. The current study addresses this issue and sheds light on how incivility perpetrated by customers can motivate service sabotage among hotel frontline employees.

Second, we draw on the theoretical perspective of equity theory, rather than the commonly used resources perspective, resulting in new and comprehensive insights into the association between customer incivility and service sabotage. This approach contributes to the knowledge on the underlying mechanisms of customer incivility and service sabotage and provides a framework for understanding how customer incivility affects service sabotage through revenge motivation. We also contribute to equity theory by showing that service employees might regard their time, motivation, and energy as inputs that they compare to their returns from customers. Given their investment, employees expect fair returns from customers; when these expectations are not fulfilled and they experience incivility instead, they develop a sense of inequity, increasing the likelihood of revenge motivation or service sabotage toward customers.

Third, we show that emotion regulation strategies are important factors, as they moderate the effect of customer incivility on revenge motivation. Specifically, cognitive reappraisal alleviates the detrimental influence of customer incivility on revenge motivation, whereas expressive suppression amplifies it. By examining the moderating effect of emotion regulation, the present study identifies new and essential boundary conditions, according to which 
customer incivility can be more or less harmful based on employees' psychological responses.

\section{Practical implications}

Our findings have several implications for hospitality managers and are especially useful for human resources managers in hotel enterprises. First, we found that frontline service employees who experience customer incivility are more likely to hold high levels of revenge motivation and engage in service sabotage. Although customer incivility can be difficult to identify (Arnold and Walsh, 2015), hotel managers should pay careful attention to it and attempt to monitor and deter the emergence of these uncivil behaviors. They can encourage employees to proactively report customer incivility and ask for help from their direct supervisors. Furthermore, hotel managers can provide psychological support for employees experiencing customer incivility to strengthen their confidence in handling those stressors. For example, due to the ambiguous nature of customer incivility (Kim and Qu, 2019; Sliter et al., 2010; Torres et al., 2017), managers can provide guidance and assistance to victimized employees to help them analyze the causes of incivility and recognize whether such incivility was initiated by them or due to the ignorance of customers, reducing the adverse effects. In addition, hotel managers can consider giving their service employees increased autonomy to deal with incivility situations (Kim and Qu, 2019), which can heighten the employees' sense of control in ongoing service encounters and reduce the level of stress associated with handling these events.

Second, our study demonstrated that employees with different emotion regulation strategies report different levels of revenge motivation, which are reflected in different levels of risk that they will engage in service sabotage. Hotel managers should provide training programs (e.g., collective learning) that teach employees adaptive emotion regulation strategies and encourage employees to deal with incivility situations using cognitive reappraisal rather than expressive suppression. Moreover, as individuals' use of particular emotion regulation strategy may be relatively fixed, hotel managers should seek to identify during the recruitment process whether candidates use reappraisal or suppression approaches to modulate their emotions. Accordingly, during recruitment, it is recommended to administer a test of emotion regulation preference: candidates who use cognitive reappraisal are less likely to be influenced by customer incivility 
and should be given priority.

In line with equity theory, frontline hotel service employees can also compare their inputs to their returns in service encounters and attempt to achieve equity between the two (Adams, 1963, 1965). As customer incivility can lead to employee perceptions of unfairness in the employee-customer social exchange and result in unfavorable consequences, hotel managers should focus on creating and maintaining a fair environment to decrease the negative effects of customer incivility and encourage employees to continuously provide high-quality service. For example, hotels enterprises can set up compensation mechanisms by offering monetary recompense, spiritual encouragement, or other support to employees who have suffered incivility from customers. Measures of this kind will reduce employees' sense of unfairness and thereby lessen the likelihood that they will engage in acts of retaliation.

\section{Limitations and future research}

This study has some limitations. The first concerns the research design. Although we used multi-wave and multi-source methods, the results might still be affected by common method bias. For example, customer incivility and revenge motivation were measured from the same source (i.e., employees), and customer incivility and emotion regulation were measured during the same wave. Future studies should use alternative research designs to reduce further the risk of common method bias. There are also possible deficiencies related to how we measured service sabotage through the assessments of the employees' direct supervisors, as sabotage is likely to be performed surreptitiously and hidden from supervisors to avoid negative consequences. Future research should adopt more accurate and reasonable methods to measure service sabotage.

Furthermore, although equity theory provides a new perspective for understanding the effects of customer incivility on revenge motivation and service sabotage, other theoretical perspectives could explain the underlying mechanisms. Moreover, since our results show a partial mediating effect of revenge motivation on the relationship between customer incivility and service sabotage, this indicates that other mediating mechanisms exist and should be explored in future research. For example, organizational culture is regarded as vital in 
stimulating employees and plays a crucial role in service performance in hotel contexts (Rahimi and Gunlu, 2016; Tsui et al., 2006). If the organizational culture is good and a hotel is serviceoriented, employees are likely to receive better training in customer service, enhancing their performance and decreasing the chances of service sabotage. This potential mechanism should be further considered in future research.

Finally, our sample was limited to service employees in Shenzhen, China, which limits the study's generalizability. Given that Chinese culture emphasizes harmonious interpersonal relationships, service employees there might have different perceptions of customer incivility from those in other countries. Thus, future studies should be conducted in different cultural contexts.

\section{References}

Abubakar, A.M. and Arasli, H. (2016), "Dear top management, please don't make me a cynic: Intention to sabotage", Journal of Management Development, Vol. 35 No. 10, pp. 12661286.

Adams, J.S. (1963), "Towards an understanding of inequity", Journal of Abnormal Psychology, Vol. 67 No. 5, pp. $422-436$.

Adams, J.S. (1965), "Inequity in social exchange", Advances in Experimental Social Psychology, Vol. 2 No. 4, pp. 267-299.

Aiken, L.S. and West, S.G. (1991), Multiple regression: Testing and interpreting interactions, Sage Publications, Newbury Park, CA.

Ambrose, M.L., Seabright, M.A. and Schminke, M. (2002), "Sabotage in the workplace: The role of organizational injustice", Organizational Behavior and Human Decision Processes, Vol. 89 No. 1, pp. 947-965.

Anderson, J.C. and Gerbing, D.W. (1988), "Structural equation modeling in practice: A review and recommended two-step approach", Psychological Bulletin, Vol. 103 No. 3, pp. 411423.

Andersson, L. and Pearson, C.M. (1999), "Tit for tat? The spiraling effect of incivility in the workplace", Academy of Management Review, Vol. 24 No. 3, pp. 452-471.

Armstrong, J.S. and Overton, T.S. (1977), "Estimating nonresponse bias in mail surveys", Journal of Marketing Research, Vol. 14 No. 3, pp. 396-402.

Arnold, K.A. and Walsh, M.M. (2015), "Customer incivility and employee well-being: Testing the moderating effects of meaning, perspective taking and transformational leadership", Work and Stress, Vol. 29 No. 4, pp. 362-378.

Bedi, A. and Schat, A.C. (2017), "Employee revenge against uncivil customers", Journal of Services Marketing, Vol. 31 No. 6, pp. 636-649.

Bennett, R.J. and Robinson, S.L. (2000), "Development of a measure of workplace 
deviance", Journal of Applied Psychology, Vol. 85 No. 3, pp. 349-360.

Ben-Zur, H. and Yagil, D. (2005), "The relationship between empowerment, aggressive behaviours of customers, coping, and burnout", European Journal of Work and Organizational Psychology, Vol. 14 No. 1, pp. 81-99.

Brislin, R.W. (1970), "Back-translation for cross-cultural research", Journal of Cross-Cultural Psychology, Vol. 1 No. 3, pp. 185-216.

Cheung, G.W. and Rensvold, R.B. (2002), "Evaluating goodness-of-fit indexes for testing measurement invariance", Structural Equation Modeling, Vol. 9 No. 2, pp. 233-255.

Chi, N.W., Chang, H.T. and Huang, H.L. (2015), "Can personality traits and daily positive mood buffer the harmful effects of daily negative mood on task performance and service sabotage? A self-control perspective", Organizational Behavior and Human Decision Processes, Vol. 131, pp. 1-15.

Chi, N.W. and Grandey, A.A. (2019), "Emotional labor predicts service performance depending on activation and inhibition regulatory fit", Journal of Management, Vol. 45 No. 2, pp. 673-700.

Cho, M., Bonn, M.A., Han, S.J. and Lee, K.H. (2016), "Workplace incivility and its effect upon restaurant frontline service employee emotions and service performance", International Journal of Contemporary Hospitality Management, Vol. 28 No. 12, pp. 2888-2912.

Cortina, L.M. and Magley, V.J. (2009), "Patterns and profiles of response to incivility in the workplace", Journal of Occupational Health Psychology, Vol. 14 No. 3, pp. 272-288.

Crino, M.D. (1994), “Employee sabotage: A random or preventable phenomenon?", Journal of Managerial Issues, Vol. 6 No. 3, pp. 311-330.

Edwards, J.R. and Lambert, L.S. (2007), "Methods for integrating moderation and mediation: A general analytical framework using moderated path analysis", Psychological Methods, Vol. 12 No. 1, pp. 1-22.

Greenberg, J. (1987), “A taxonomy of organizational justice theories”, Academy of Management Review, Vol. 12 No. 1, pp. 9-22.

Gregoire, Y., Tripp, T.M. and Legoux, R. (2009), "When customer love turns into lasting hate: The effects of relationship strength and time on customer revenge and avoidance", Journal of Marketing, Vol. 73 No. 6, pp. 18-32.

Gross, J.J. (1998), "Antecedent- and response-focused emotion regulation: Divergent consequences for experience, expression, and physiology", Journal of Personality and Social Psychology, Vol. 74 No. 1, pp. 224-37.

Gross, J.J. and John, O.P. (2003), "Individual differences in two emotion regulation processes: Implications for affect, relationships, and well-being", Journal of Personality and Social Psychology, Vol. 85 No. 2, pp. 348-362.

Han, S.J., Bonn, M.A. and Cho, M. (2016), "The relationship between customer incivility, restaurant frontline service employee burnout and turnover intention", International Journal of Hospitality Management, Vol. 52, pp. 97-106.

Harman, H. (1976), Modern Factor Analysis, University of Chicago, Chicago IL.

Harris, L.C. and Ogbonna, E. (2002), "Exploring service sabotage: The antecedents, types and consequences of frontline, deviant, antiservice behaviors", Journal of Service Research, Vol. 4 No. 3, pp. 163-183.

Harris, L.C. and Ogbonna, E. (2006), "Service sabotage: A study of antecedents and 
consequences", Journal of the Academy of Marketing Science, Vol. 34 No. 4, pp. 543-558.

Hayes, A.F. (2013), Introduction to mediation, moderation and conditional process analysis: A regression-based approach, Guilford Press, New York, NY.

Henkel, A.P., Boegershausen, J., Rafaeli, A. and Lemmink, J. (2017), "The social dimension of service interactions: Observer reactions to customer incivility", Journal of Service Research, Vol. 20, No. 2, pp. 120-134.

Huang, Z. and Miao, L. (2016), "Illegitimate customer complaining behavior in hospitality service encounters: A frontline employee perspective", Journal of Hospitality and Tourism Research, Vol. 40 No. 6, pp. 655-684.

Hur, W.M., Moon, T. and Jun, J.K. (2016), "The effect of workplace incivility on service employee creativity: The mediating role of emotional exhaustion and intrinsic motivation", Journal of Services Marketing, Vol. 30 No. 3, pp. 302-315.

Hur, W.M., Moon, T.W. and Han, S.J. (2015), "The effect of customer incivility on service employees' customer orientation through double-mediation of surface acting and emotional exhaustion", Journal of Service Theory and Practice, Vol. 25 No. 4, pp. 394-413.

Joormann, J. and Gotlib, I.H. (2010), "Emotion regulation in depression: Relation to cognitive inhibition", Cognition and Emotion, Vol. 24 No. 2, pp. 281-298.

Kashif, M., Braganca, E., Awang, Z. and De Run, E.C. (2017), "You abuse but I will stay: The combined effects of job stress, customer abuse, and emotional intelligence on employee turnover", Journal of Management Development, Vol. 36 No. 7, pp. 899-914.

Kern, J.H. and Grandey, A.A. (2009), "Customer incivility as a social stressor: The role of race and racial identity for service employees", Journal of Occupational Health Psychology, Vol. 14 No. 1, pp. 46-57.

Kim, H. and Qu, H. (2019), "The effects of experienced customer incivility on employees' behavior toward customers and coworkers", Journal of Hospitality and Tourism Research, Vol. 43 No. 1, pp. 58-77.

Lee, J.H. and Ok, C.M. (2014), “Understanding hotel employees' service sabotage: Emotional labor perspective based on conservation of resources theory", International Journal of Hospitality Management, Vol. 36, pp. 176-187.

Lyu, Y., Zhou, X., Li, W., Wan, J. and Qiu, C. (2016), "The impact of abusive supervision on service employees' proactive customer service performance in the hotel industry", International Journal of Contemporary Hospitality Management, Vol. 28 No. 9, pp. 19922012.

McCullough, M.E., Rachal, K.C., Sandage, S.J., Worthington, E.L., Brown, S.W. and Hight, T.L. (1998), "Interpersonal forgiving in close relationships: II. Theoretical elaboration and measurement", Journal of Personality and Social Psychology, Vol. 75 No. 6, pp. 15861603.

Podsakoff, P.M., Mackenzie, S.B., Lee, J. and Podsakoff, N.P. (2003), "Common method biases in behavioral research: A critical review of the literature and recommended remedies", Journal of Applied Psychology, Vol. 88 No. 5, pp. 879-903.

Podsakoff, P.M., Mackenzie, S.B. and Podsakoff, N.P. (2012), "Sources of method bias in social science research and recommendations on how to control it", Annual Review of Psychology, Vol. 63 No. 1, pp. 539-569.

Rahimi, R. and Gunlu, E. (2016), "Implementing customer relationship management (CRM) in 
hotel industry from organizational culture perspective: Case of a chain hotel in the UK", International Journal of Contemporary Hospitality Management, Vol. 28 No. 1, pp. 89-112.

Robinson, S.L. and Bennett, R.J. (1995), "A typology of deviant workplace behaviors: A multidimensional scaling study", Academy of Management Journal, Vol. 38 No. 2, pp. 555572.

Schumann, K. and Ross, M. (2010), "The benefits, costs, and paradox of revenge", Social and Personality Psychology Compass, Vol. 4 No. 12, pp. 1193-1205.

Shao, R. and Skarlicki, D.P. (2014), "Service employees' reactions to mistreatment by customers: A comparison between North America and East Asia”, Personnel Psychology, Vol. 67 No. 1, pp. 23-59.

Shorey, R.C., McNulty, J.K., Moore, T.M. and Stuart, G.L. (2015), "Emotion regulation moderates the association between proximal negative affect and intimate partner violence perpetration", Prevention Science, Vol. 16 No. 6, pp. 873-880.

Skarlicki, D.P., van Jaarsveld, D.D., Shao, R., Song, Y.H. and Wang, M. (2016), "Extending the multifoci perspective: The role of supervisor justice and moral identity in the relationship between customer justice and customer-directed sabotage", Journal of Applied Psychology, Vol. 101 No. 1, pp. 108-121.

Skarlicki, D.P., van Jaarsveld, D.D. and Walker, D.D. (2008), "Getting even for customer mistreatment: The role of moral identity in the relationship between customer interpersonal injustice and employee sabotage", Journal of Applied Psychology, Vol. 93 No. 6, pp. 13351347.

Sliter, M., Jex, S., Wolford, K. and McInnerney, J. (2010), "How rude! Emotional labor as a mediator between customer incivility and employee outcomes", Journal of Occupational Health Psychology, Vol. 15 No. 4, pp. 468-481.

Sliter, M., Sliter, K. and Jex, S. (2012), “The employee as a punching bag: The effect of multiple sources of incivility on employee withdrawal behavior and sales performance", Journal of Organizational Behavior, Vol. 33 No. 1, pp. 121-139.

Spaapen, D.L., Waters, F., Brummer, L., Stopa, L. and Bucks, R.S. (2014), “The emotion regulation questionnaire: Validation of the ERQ-9 in two community samples", Psychological Assessment, Vol. 26 No. 1, pp. 46-54.

Surprenant, C.F. and Solomon, M.R. (1987), "Predictability and personalization in the service encounter”, Journal of Marketing, Vol. 51 No. 2, pp. 86-96.

Torres, E.N., Niekerk, M.V. and Orlowski, M. (2017), "Customer and employee incivility and its causal effects in the hospitality industry", Journal of Hospitality Marketing and Management, Vol. 26 No. 1, pp. 48-66.

Tsui, A.S., Zhang, Z.X., Wang, H., Xin, K.R. and Wu, J.B. (2006), "Unpacking the relationship between CEO leadership behavior and organizational culture", The Leadership Quarterly, Vol. 17 No. 2, pp. 113-137.

van Jaarsveld, D.D., Walker, D.D. and Skarlicki, D.P. (2010), “The role of job demands and emotional exhaustion in the relationship between customer and employee incivility", Journal of Management, Vol. 36 No. 6, pp. 1486-1504.

Walker, D.D., Jaarsveld, D.D.V. and Skarlicki, D.P. (2014), "Exploring the effects of individual customer incivility encounters on employee incivility: The moderating roles of entity (in)civility and negative affectivity", Journal of Applied Psychology, Vol. 99 No. 1, pp. 
151-61.

Walker, D.D., van Jaarsveld, D.D. and Skarlicki, D.P. (2017), "Sticks and stones can break my bones but words can also hurt me: The relationship between customer verbal aggression and employee incivility", Journal of Applied Psychology, Vol. 102 No. 2, pp. 163-179.

Wang, M., Liao, H., Zhan, Y. and Shi, J. (2011), "Daily customer mistreatment and employee sabotage against customers: Examining emotion and resource perspectives", Academy of Management Journal, Vol. 54 No. 2, pp. 312-334.

Wilson, N.L. and Holmvall, C.M. (2013), "The development and validation of the incivility from customers scale", Journal of Occupational Health Psychology, Vol. 18 No. 3, pp. 310326.

Yeh, C. (2015), "Linking customer verbal aggression and service sabotage", Journal of Service Theory and Practice, Vol. 25 No. 6, pp. 877-896.

Zhou, X., Ma, J. and Dong, X. (2018), "Empowering supervision and service sabotage: A moderated mediation model based on conservation of resources theory", Tourism Management, Vol. 64, pp. 170-187. 
Appendix A. Items for each construct

Employee (T1)

Customer incivility (Walker et al., 2014):

"My customers spoke aggressively toward me".

"My customers used a tone when speaking with me".

"My customers asked aggressive questions (e.g., "Really?" "Are you kidding?”)".

"My customers made curt statements toward me".

\section{Cognitive reappraisal (Spaapen et al., 2014):}

"When I want to feel more positive (such as joy or amusement), I change what I'm thinking about".

"When I'm faced with a stressful situation, I make myself think about it in a way that helps me calm down".

"When I want to feel more positive emotions, I change the way I'm thinking about the situation".

"I control my emotions by changing the way I think about the situation I'm in".

"When I want to feel less negative emotions, I change the way I'm thinking about the situation".

\section{Expressive suppression (Spaapen et al., 2014):}

"I keep my emotions to myself".

"When I am feeling positive emotions, I am careful not to express them".

"I control my emotions by not expressing them".

"When I am feeling negative emotions, I make sure not to express them".

\section{Employee (T2)}

\section{Revenge motivation (McCullough et al., 1998):}

"I wanted to see that customer get what he/she deserves".

"I wished that something bad would happen to that customer".

"I was going to get even with the customer".

"I would like to make the customer pay". 
"I wanted to see the customer hurt and miserable".

\section{Supervisor (T3)}

\section{Service sabotage (Chi et al., 2015):}

"This employee mistreats customers deliberately".

"This employee intentionally hurries customers when he/she wants to".

"This employee behaves negatively toward customers".

"This employee tries to take revenge on rude customers".

“This employee ignores service rules to make things easier for him/her".

"This employee intentionally slows down service when he/she wants to". 
Table 1. Results of confirmatory factor analyses

\begin{tabular}{|c|c|c|c|c|c|c|}
\hline Model & $\chi^{2}$ & $\mathrm{df}$ & $\square \chi^{2} / \mathrm{df}$ & IFI & CFI & RMSEA \\
\hline Baseline model (five-factor model) & 522.44 & 239 & 2.19 & 0.92 & 0.92 & 0.06 \\
\hline $\begin{array}{l}\text { Four-factor model } 1: \text { cognitive reappraisal and } \\
\text { expressive suppression were combined into one factor }\end{array}$ & 845.24 & 243 & 3.48 & 0.82 & 0.82 & 0.09 \\
\hline $\begin{array}{l}\text { Four-factor model 2: customer incivility and service } \\
\text { sabotage were combined into one factor }\end{array}$ & 804.66 & 243 & 3.31 & 0.83 & 0.83 & 0.09 \\
\hline $\begin{array}{l}\text { Four-factor model 3: revenge motivation and service } \\
\text { sabotage were combined into one factor }\end{array}$ & 793.71 & 243 & 3.27 & 0.84 & 0.83 & 0.09 \\
\hline $\begin{array}{l}\text { Four-factor model 4: cognitive reappraisal and service } \\
\text { sabotage were combined into one factor }\end{array}$ & 847.26 & 243 & 3.49 & 0.82 & 0.82 & 0.09 \\
\hline $\begin{array}{l}\text { Four-factor model 5: expressive suppression and service } \\
\text { sabotage were combined into one factor }\end{array}$ & 738.04 & 243 & 3.04 & 0.85 & 0.85 & 0.08 \\
\hline $\begin{array}{l}\text { Four-factor model 6: customer incivility and cognitive } \\
\text { reappraisal were combined into one factor }\end{array}$ & 897.86 & 243 & 3.70 & 0.81 & 0.80 & 0.10 \\
\hline $\begin{array}{l}\text { Four-factor model 7: customer incivility and expressive } \\
\text { suppression were combined into one factor }\end{array}$ & 749.99 & 243 & 3.09 & 0.85 & 0.85 & 0.09 \\
\hline $\begin{array}{l}\text { Four-factor model 8: customer incivility and revenge } \\
\text { motivation were combined into one factor }\end{array}$ & 666.32 & 243 & 2.74 & 0.87 & 0.87 & 0.08 \\
\hline
\end{tabular}

Note: $N=291$; IFI = incremental fit index; $\mathrm{CFI}=$ comparative fit index; RMSEA = root-meansquare error of approximation. 
Table 2. Means, standard deviations, and correlations of all variables

\begin{tabular}{|c|c|c|c|c|c|c|c|c|c|c|c|}
\hline Variables & Mean & SD & 1 & 2 & 3 & 4 & 5 & 6 & 7 & 8 & 9 \\
\hline 1. Gender & 1.70 & 0.46 & & & & & & & & & \\
\hline 2. Age & 2.75 & 1.28 & $0.13 *$ & & & & & & & & \\
\hline 3. Education & 1.46 & 0.75 & 0.04 & -0.10 & & & & & & & \\
\hline 4. Tenure & 2.14 & 1.12 & 0.05 & $0.47 * *$ & $0.16^{* *}$ & & & & & & \\
\hline 5. Customer incivility & 2.39 & 0.63 & $-0.15^{*}$ & 0.02 & 0.03 & -0.01 & $(0.78)$ & & & & \\
\hline 6. Revenge motivation & 2.45 & 0.66 & $-0.14^{*}$ & -0.07 & 0.01 & -0.06 & $0.42 * *$ & (0.79) & & & \\
\hline 7. Cognitive reappraisal & 3.83 & 0.52 & 0.11 & 0.05 & 0.05 & $0.13 *$ & -0.11 & $-0.18 * *$ & $(0.72)$ & & \\
\hline 8. Expressive suppression & 2.82 & 0.76 & $-0.13^{*}$ & $-0.14 *$ & $0.21 * *$ & $-0.13 *$ & $0.17 * *$ & $0.24 * *$ & -0.07 & $(0.75)$ & \\
\hline 9. Service sabotage & 2.05 & 0.98 & $-0.18 * *$ & -0.11 & 0.11 & -0.02 & $0.32 * *$ & $0.31 * *$ & $-0.26^{* *}$ & $0.30 * *$ & $(0.94)$ \\
\hline
\end{tabular}

Notes: $N=291 .{ }^{*} p<0.05 ;{ }^{* *} p<0.01$. Cronbach's alphas appear in parentheses along the diagonal. Gender: " 1 " = male; " $2 "=$ female. Age: "1" = 20 years old or below; "2" = 21-30 years old; "3" = 31-40 years old; "4" = 41-50 years old; and " 5 " = 51 years old or above. Education: "1" = high school degree or below; " 2 " = junior college degree; "3" = bachelor's degree; " 4 " = master's degree or above. Tenure: "1" = 1 year or less; "2" = 2-3 years; "3" $=3-5$ years; " 4 " $=5-7$ years; " 5 " = more than 7 years. 
Table 3. Results of hypothesis testing

\begin{tabular}{lcccccccc}
\hline & \multicolumn{3}{c}{ Revenge motivation } & \multicolumn{3}{c}{ Service sabotage } \\
\cline { 2 - 8 } & M1 & M2 & M3 & M4 & M6 & M7 & M8 & M9 \\
\hline Control variable & & & & & & & & \\
Gender & $-0.14^{*}$ & -0.07 & -0.02 & -0.00 & $-0.17^{* *}$ & $-0.13^{*}$ & $-0.13^{*}$ & $-0.11^{*}$ \\
Age & -0.03 & -0.06 & -0.05 & -0.04 & -0.08 & -0.10 & -0.08 & -0.09 \\
Education & 0.02 & -0.00 & -0.04 & -0.04 & 0.11 & 0.09 & 0.10 & 0.09 \\
Tenure & -0.04 & -0.03 & 0.01 & 0.02 & 0.01 & 0.02 & 0.02 & 0.03 \\
\hline
\end{tabular}




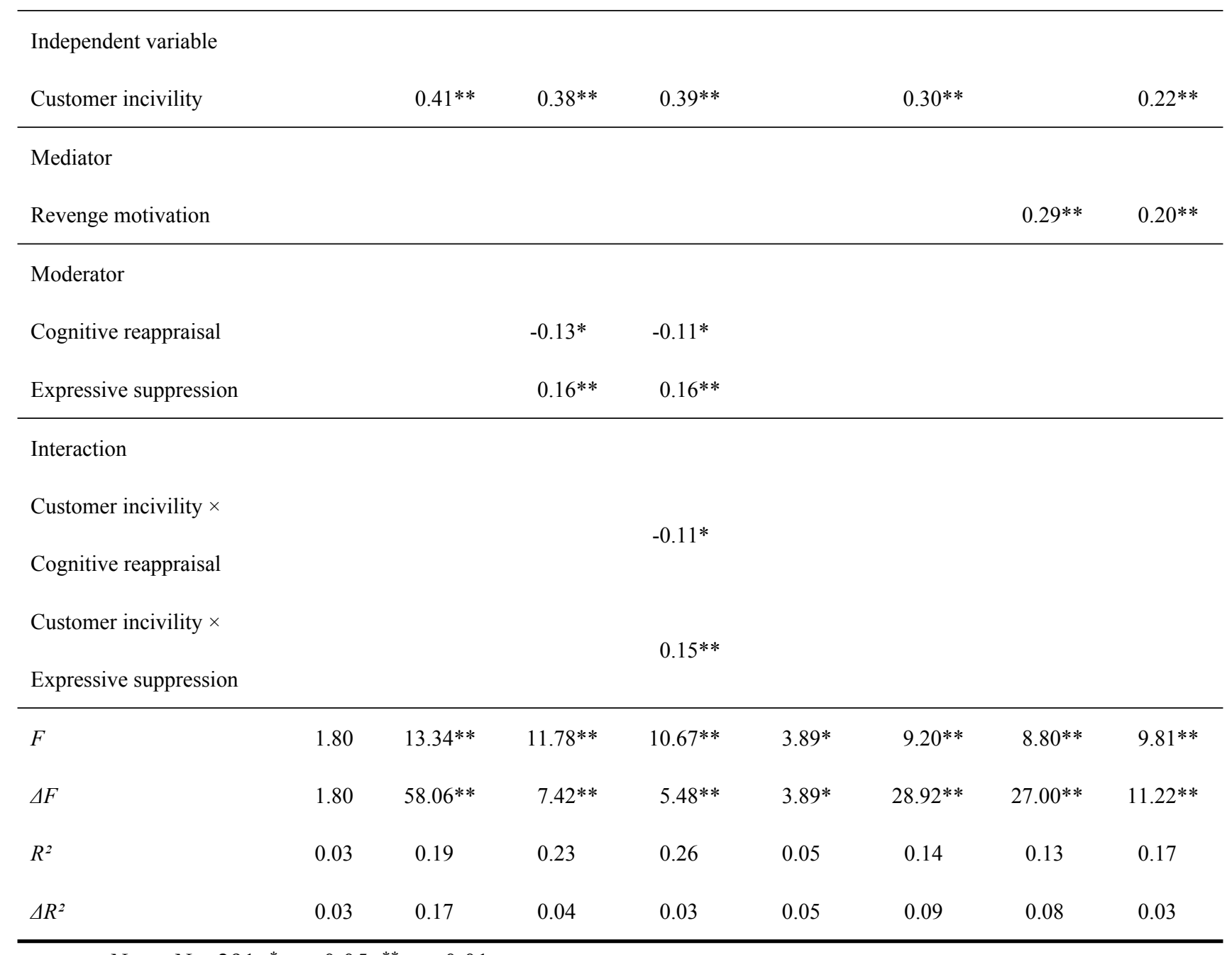

Note: $N=291 ;{ }^{*} p<0.05 ;{ }^{* *} p<0.01$. 


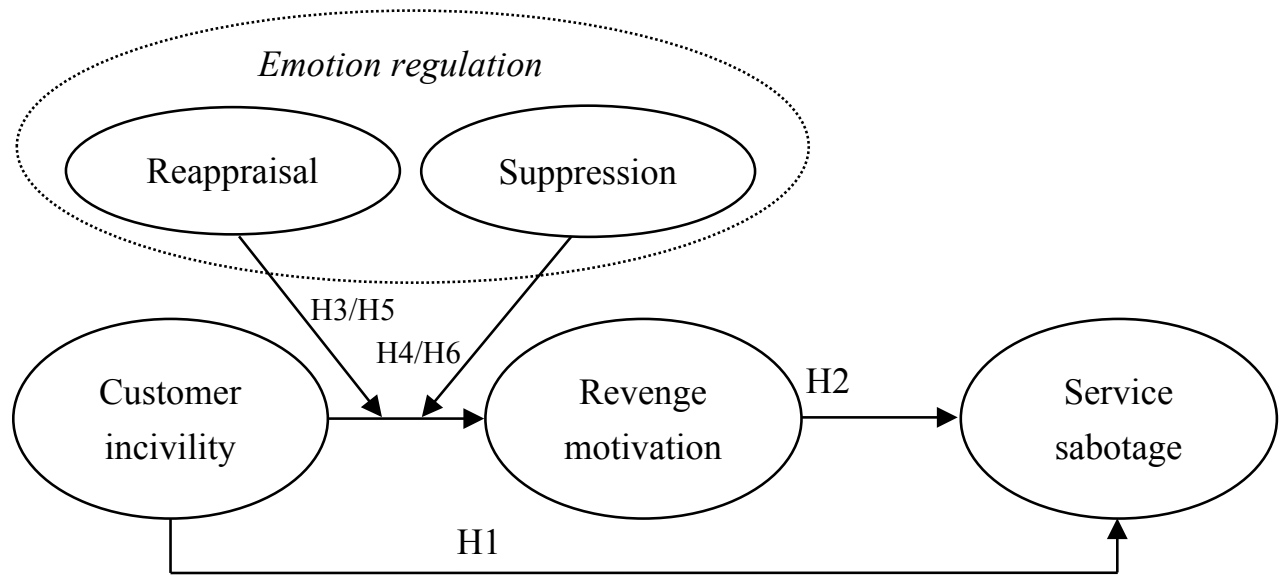

Figure 1. Conceptual model 


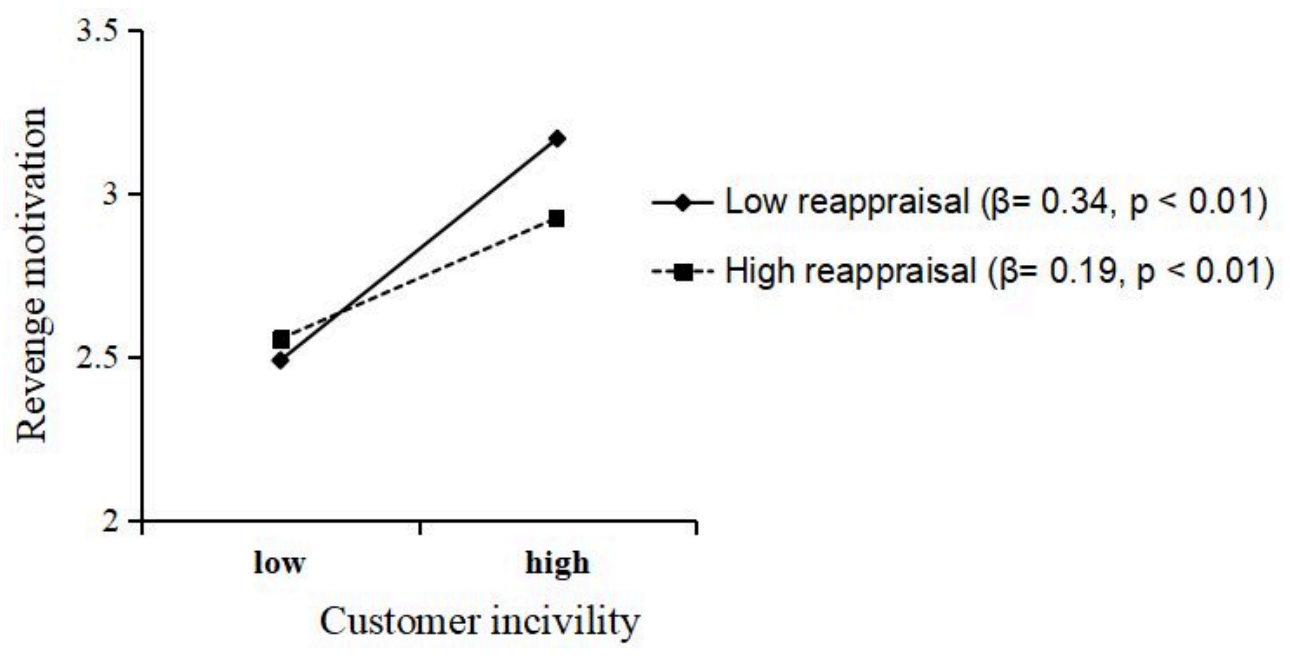

Figure 2. Interactive effects of customer incivility and cognitive reappraisal on revenge motivation 


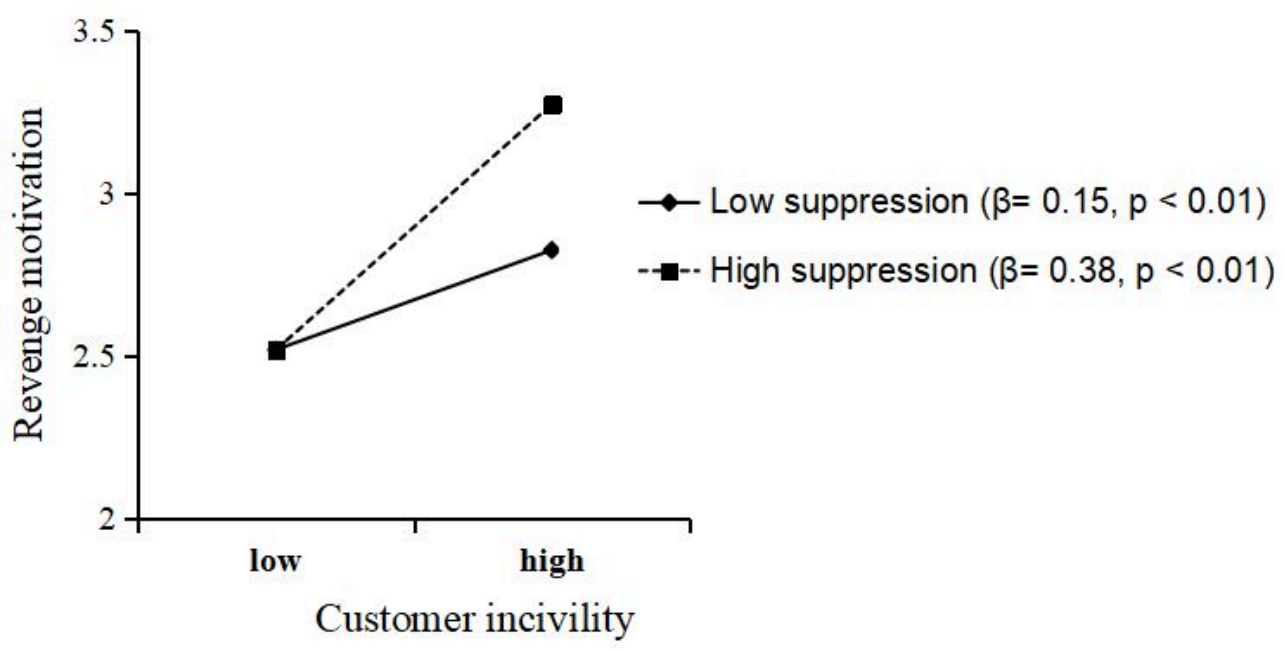

Figure 3. Interactive effects of customer incivility and expressive suppression on revenge motivation 